\title{
Toll-like receptor 4 signaling promotes epithelial- mesenchymal transition in human hepatocellular carcinoma induced by lipopolysaccharide
}

\author{
Ying-Ying Jing ${ }^{\dagger}$, Zhi-Peng Han ${ }^{\dagger}$, Kai Sun ${ }^{\dagger}$, Shan-Shan Zhang, Jing Hou, Yan Liu, Rong Li, Lu Gao, Xue Zhao,
} Qiu-Dong Zhao, Meng-Chao Wu and Li-Xin Wei

\begin{abstract}
Background: The endotoxin level in the portal and peripheral veins of hepatocellular carcinoma (HCC) patients is higher and lipopolysaccharide (LPS), a cell wall constituent of gram-negative bacteria, has been reported to inhibit tumor growth. However, in this study, we found that LPS-induced toll-like receptor 4 (TLR4) signaling was involved in tumor invasion and survival, and the molecular mechanism was investigated,

Methods: Four HCC cell lines and a splenic vein metastasis of the nude mouse model were used to study the invasion ability of LPS-induced HCC cells and the epithelia-mesenchymal transition (EMT) in vitro and in vivo.

A total of 106 clinical samples from HCC patients were used to evaluate TLR4 expression and analyze its association with clinicopathological characteristics

Results: The in vitro and in vivo experiments demonstrated that LPS could significantly enhance the invasive potential and induce EMT in HCC cells with TLR4 dependent. Further studies showed that LPS could directly activate nuclear factor kappa B (NF- $\kappa$ B) signaling through TLR4 in HCC cells. Interestingly, blocking NF- $\kappa$ B signaling significantly inhibited transcription factor Snail expression and thereby inhibited EMT occurrence. High expression of TLR4 in HCC tissues was strongly associated with both poor cancer-free survival and overall survival in patients.

Conclusions: Our results indicate that TLR4 signaling is required for LPS-induced EMT, tumor cell invasion and metastasis, which provide molecular insights for LPS-related pathogenesis and a basis for developing new strategies against metastasis in HCC.
\end{abstract}

Keywords: Toll-like receptor 4, Epithelial-mesenchymal transition, Lipopolysaccharide, Human hepatocellular carcinoma

\section{Background}

Persistent inflammatory conditions can induce tumorigenesis [1]. Hepatocellular carcinoma (HCC) is closely associated with chronic inflammatory liver diseases and the endotoxin level in the portal and peripheral veins of those patients is higher owing to changes in the intestinal mucosal permeability and increased bacterial infection [2-4]. Lipopolysaccharide (LPS), a cell wall constituent of gramnegative bacteria, is released during lysis of bacteria. It has been reported that LPS can induce cytokines from

\footnotetext{
*Correspondence: weilixin@yahoo.com

† Contributed equally

Tumor Immunology and Gene Therapy Center, Eastern Hepatobiliary Surgery Hospital, Second Military Medical University, Shanghai, PR China
}

immune cells and inhibit tumor growth [5,6], but recent studies have shown that LPS can alter cytokine levels in the tumor microenvironment and exert direct effects on tumor cell proliferation, invasion and metastasis in vitro and in vivo [7-10].

Toll-like receptor 4 (TLR4), the receptor for LPS, is not only important in the regulation of immune responses to infection [11], but also is involved in noninfectious inflammatory diseases, such as tumor invasion and survival [12]. TLR4 has been detected in many human cancer cell lines, including pancreatic, lung, breast, prostate, liver and colorectal cancer $[10,12-16]$. When silencing TLR4 expression, the invasion, survival, and tumorigenicity of human prostate cancer cells was inhibited, which 
indicates TLR4 plays a significant role in connecting inflammation and cancer invasion and progression [12]; however, the exact mechanism is still not clear.

Epithelial to mesenchymal transition (EMT) is a process in which epithelial cell layers lose polarity together with cell to cell contacts which results in a dramatic remodeling of the cytoskeleton, and has an important role in tumor metastasis [17]. When human intrahepatic biliary epithelial cells (IBECs) were exposed to high levels of LPS, the IBECs could undergo EMT, potentially contributing to hepatic fibrosis or even hepatoma [18]. In HCC tissues, LPS was previously reported to promote adhesion and invasion in hepatoma cells [9]. These effects suggest that LPS-induced TLR4 signaling provides a survival benefit for metastatic tumors; however, whether TLR4 signaling can induce EMT in HCC cells and the mechanism involved remains unclear.

In the present study, we provide evidence that LPSinduced TLR4 signaling promotes HCC cell invasion and EMT in vitro and in vivo, and a high expression of TLR4 in HCC tissues was strongly associated with both poor cancer-free survival and overall survival in patients, which indicates that LPS is closely related to tumor invasion and metastasis, rather than only anti-tumor effects.

\section{Methods}

\section{Reagents and antibodies}

(Dulbecco's) modified Eagle's medium ((D)MEM), fetal bovine serum (FBS), penicillin, streptomycin sulfate, glutamine, and $0.05 \%$ trypsin $/ 0.02 \%$ ethylenediamine tetraacetic acid (EDTA) solution were purchased from Invitrogen (Carlsbad, CA, USA). LPS derived from Escherichia coli strain 055:B5, Trizol, Lipofectamine 2000 and BAY11-7028, the inhibitor of nuclear factor kappa B (NF- $\kappa \mathrm{B})$, were purchased from Sigma (St. Louis, MO, USA). A dual luciferase reporter gene assay kit to detect NF- $\kappa$ B activity was purchased from Promega (Madison, WI, USA). Rabbit antihuman E-cadherin and Vimentin antibodies were obtained from Thermo (Fremont, CA, USA). Goat anti-human Snail antibody was purchased from R\&D (Minneapolis, MN, USA). Rabbit anti-human TLR4 antibody was purchased from Bioworld Technology (St. Louis, MN, USA).

\section{Cell lines and culture condition}

HCC cell lines (HepG2, Huh7, Hep3B, SMMC-7721 and MHCC97-H) were cultured in (D)MEM supplemented with $10 \% \mathrm{FBS}, 100 \mathrm{U} / \mathrm{ml}$ penicillin, $100 \mu \mathrm{g} / \mathrm{ml}$ streptomycin sulfate, and $2.0 \mathrm{mM}$ glutamine. Cells were maintained at $37^{\circ} \mathrm{C}$ in a humidified $5 \% \mathrm{CO}_{2}$ atmosphere and subcultured by trypsinization with $0.05 \%$ trypsin/0.02\% EDTA when cells became confluent. For LPS treatment, subconfluent cultures of cells were treated with $10 \mu \mathrm{g} / \mathrm{ml}$ LPS for 48 hours. For NF- $\kappa$ B inhibition, $10 \mu \mathrm{M}$ BAY11-7028 was added to the cell culture at the same time as LPS.

\section{Patients and tissue specimens}

Specimens of HCC tissues were obtained from 106 HCC patients who underwent hepatic resection at the Eastern Hepatobiliary Surgery Hospital of the Second Military Medical University from October 2000 to November 2003. These patients included 88 men and 18 women with a median age of 49 years (range: 11 to 72 ), and all of the specimens were subjected to immunohistochemisty (IHC). Prior informed consent was obtained and the study protocol was approved by the Ethics Committee of the Eastern Hepatobiliary Surgery Hospital.

\section{Wound healing and Transwell assay}

The methods for wound healing and the Transwell assay have been described [19-21]. For the wound-healing assay, cells $\left(5 \times 10^{4}\right)$ were seeded on a 24-well dish and incubated for 24 hours, the monolayer was then disrupted with a cell scraper (1.2 $\mathrm{mm}$ width), and photographs were taken at 0 and 48 hours in a phase-contrast microscope. Experiments were carried out in triplicate, and four fields of each point were recorded. For the Transwell assay, Boyden chambers $(8 \mu \mathrm{m}$ pore size) were coated with $200 \mu \mathrm{l}$ Matrigel at $200 \mu \mathrm{g} / \mathrm{ml}$ and incubated overnight. Cells $\left(5 \times 10^{4}\right)$ in medium without serum were plated in the upper chamber, and the medium containing $5 \%$ FBS was added in the lower chamber as a chemoattractant. After 24 hours of incubation at $37^{\circ} \mathrm{C}$, the cells were fixed in $4 \%$ formaldehyde and stained with crystal violet dye, and the cells that invaded through the pores to the lower surface of the filter were counted under a microscope. Three invasion chambers were used per condition. The values obtained were calculated by averaging the total number of cells from three filters.

\section{Nude mouse splenic vein metastasis assay}

All procedures involving animals were performed in accordance with the institutional animal welfare guidelines of the Second Military Medical University. Cells were injected into the splenic vein of eight-week-old nude mice (BALB/c strain) at $1 \times 10^{6}$ cells/injection site. The mice were sacrificed after six weeks and the numbers of surface liver metastases were counted.

\section{Quantitative real-time polymerase chain reaction (qPCR)}

Total RNA extraction, complementary DNA (cDNA) synthesis, and qPCR were performed as described [22]. The primer sequences used in qPCR are shown in Additional file 1 Table S1.

\section{Western-blot analysis}

Total soluble protein extractions from cultivated cells and western-blot analysis were performed as described [22]. Antibodies used in western-blot experiments were specific for TLR4, Snail or E-cadherin. 


\section{Immunofluorescence}

About $10^{4}$ cells were seeded on a 48-well dish. After 24 hours, the cells were washed twice with PBS, and fixed in $4 \%$ paraformaldehyde and $0.1 \%$ Triton $\times 100$ in PBS buffer at $4^{\circ} \mathrm{C}$ for 30 minutes. After being washed with $\mathrm{PBS}$, the cells were incubated with the blocking solution (10\% goat serum in PBS), and then incubated overnight with the primary antibodies, washed with PBS, and finally incubated with secondary antibodies at $37^{\circ} \mathrm{C}$ for 2 hours. After being stained with DAPI/PI (4', 6-diamidino-2-phenylindole/ propidium iodide), all matched samples were photographed using an immunofluorescence microscope and identical exposure times.

\section{FACS Analysis}

The expression of TLR4 on HCC cells was determined using indirect immunofluorescent staining. In this analysis, $20 \mu \mathrm{l}$ of anti-TLR4 antibody were added to $100 \mu \mathrm{l}$ of cell suspension $\left(1 \times 10^{6}\right.$ cells $\left./ \mathrm{ml}\right)$ and incubated at $4^{\circ} \mathrm{C}$ for 30 minutes, and further stained with secondary fluorescein isothiocyanate (FITC)-conjugated antibody at $4^{\circ} \mathrm{C}$ for 30 minutes. FITC-conjugated isotype IgG antibody was used as a negative control. The stained cells were analyzed on a FACS flow cytometer (Becton Dickinson, San Jose, CA, USA).

\section{Generation of stable TLR4-expressed and knocked-down cell lines}

The adeno-associated viral construct which directs the expression of TLR4 (pAAV-TLR4-IRES-GFP), siRNA against TLR4 (pAAV-siTLR4-IRES-GFP) and their control vectors were constructed and verified by DNA sequencing. The adeno-associated viral construct that expresses TLR4 or siRNA targeting TLR4 were co-transfected with adenoassociated viral packaging plasmids pAAV-RC, pAAVhelper into 293T cells by Lipofectamine 2000 according to the manufacturer's instructions. At 24 and 48 hours posttransfection, culture medium was collected to be incubated with target cells. At 48 hours post-infection, infected cells were harvested for gene and protein expression analysis or selected with $\mathrm{G} 418(400 \mu \mathrm{g} / \mathrm{ml})$ for two weeks to establish stable clones.

\section{NF- $\kappa$ B luciferase reporter assays}

$\mathrm{NF}-\kappa \mathrm{B}$ luciferase reporter assays were performed as described previously [23]. Briefly, cells were co-transfected with a pNF- $\kappa$ B-luc reporter construct and a renilla luciferase-expressing plasmid (internal control to normalize for transfection efficiency) using Lipofectamine 2000 according to the manufacturer's instructions. After treatment for 48 hours, firefly and renilla luciferase activities were assessed using a dual luciferase reporter gene assay kit. $\mathrm{NF}-\kappa \mathrm{B}$ transcriptional activity = relative light units of firefly luciferase/relative light units of renilla luciferase.

\section{IHC analysis}

The sample processing and IHC procedures were performed as described [20] and the results were expressed as the percentage of tumor cells with a positive stain. Thereafter, the percentage of TLR4-positive tumor cells was scored on a scale of 0 to 4 (0: no staining; 1 : $\leq 10 \%$; 2 : $11 \%$ to $30 \%$; $3: 31 \%$ to $50 \%$; $4: \geq 50 \%$ ). Furthermore, the expression level of TLR4 was divided into the following two groups according to score: low $(0,1,2)$ and high $(3,4)$ [16].

\section{Statistical analysis}

All data, expressed as mean \pm the standard error of the mean (SEM), were from at least three separate experiments. Groups were compared by analysis of variance (ANOVA) with a posteriori contrast by least significant difference; or by Student t-test using the Microsoft Excel Analysis ToolPak (Microsoft, Redmond, WA). $P<0.05$ was considered significant.

\section{Results}

\section{LPS induces metastasis and invasion of HCC cells lines}

Four different human HCC cell lines (HepG2, Huh7, Hep3B, and SMMC-7721) were tested for the scratch wound-healing and Matrigel invasion assay. In HepG2 and Huh9 cells, no obvious effects on motility and invasion were observed in the presence of LPS stimulation $(10 \mu \mathrm{g} / \mathrm{ml})$ for 48 hours, and the effect in Hep3B cells was also limited. In contrast, the motility and invasion abilities of SMMC-7721 cells were enhanced significantly (Figure 1A, B, P < 0.05). We next chose HepG2, the least invasive cell line, and SMMC-7721, the most invasive one, for the splenic vein metastasis assay in vivo. Subconfluent monolayer cultures of cells were treated with or without LPS for 48 hours, and then were injected intrasplenically into athymic nude mice. After six to eight weeks, mice injected with LPS-treated or -untreated HepG2 cells had no difference in the number of liver surface metastatic nodules; however, the mice injected with LPS-treated SMMC-7721 cells had a significantly higher number of liver surface metastatic nodules compared to those with untreated cells (Figure $1 \mathrm{C}, \mathrm{D}, \mathrm{P}<0.05$ ). The survival rate of mice showed a similar trend (Figure 1E). These results indicate that LPS has diverse effects on the metastatic potential of HCC cell lines.

\section{LPS induces EMT in cells with higher expression of TLR4}

Cell scattering was observed in SMMC-7721 cells treated with LPS, while no phenotypic changes were observed in the other cell lines (HepG2, Huh7 and Hep3B) (Figure 2A). Consistent with LPS promoting SMMC-7721 cell invasion, the mesenchymal markers (Vimentin, N-cadherin, and $\alpha$-smooth muscle actin ( $\alpha$-SMA)) were upregulated and epithelial markers (E-cadherin and $\beta$-catenin) were 


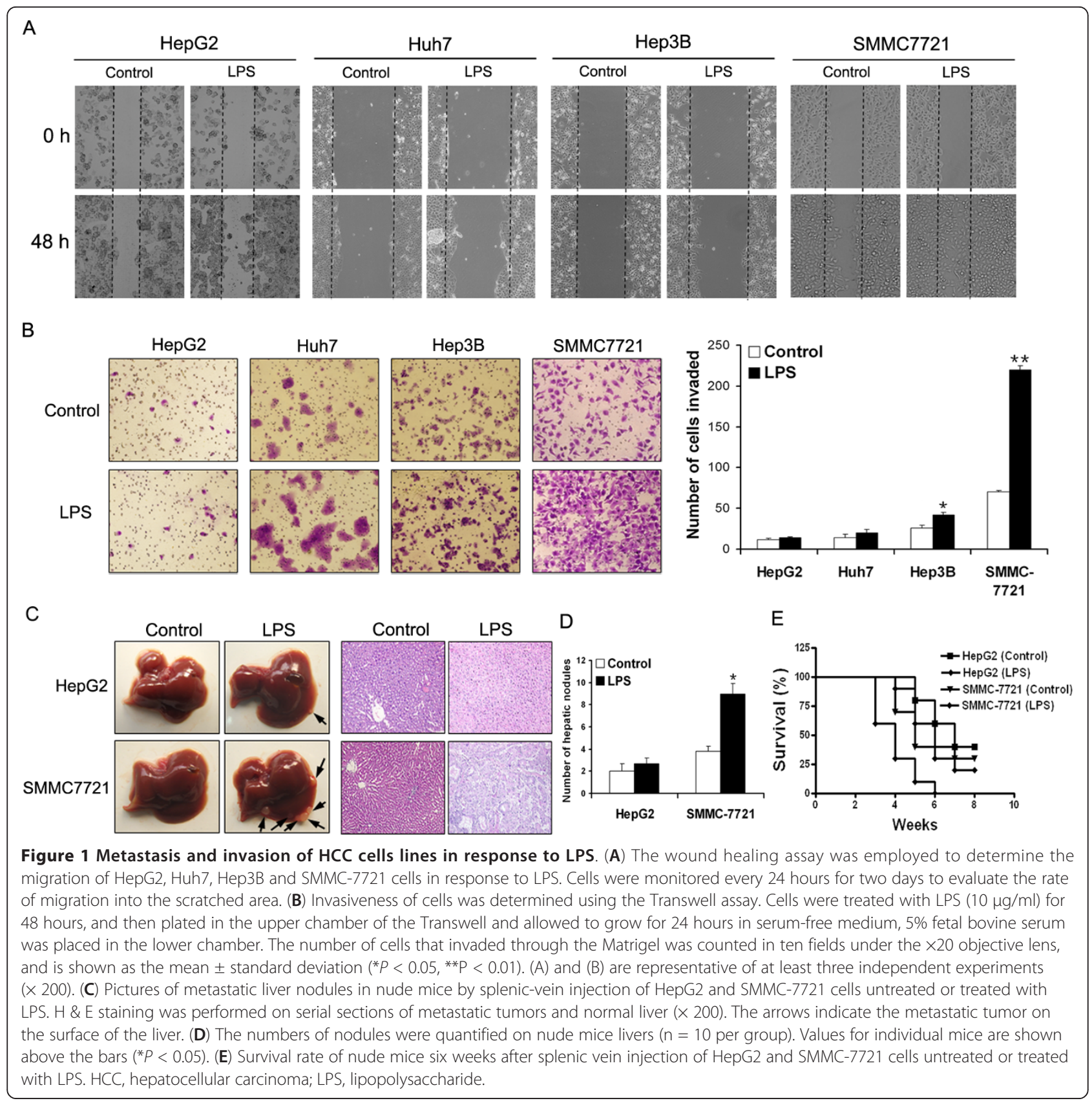

downregulated. LPS did not induce EMT in HepG2, Huh7 and Hep3B cells (Figure 2B). The immunofluorescence results of E-cadherin and Vimentin further support the finding that LPS induced EMT in SMMC-7721 cells but not in HepG2 cells (Figure 2C).

\section{LPS-induced metastasis and EMT in HCC cells are dependent on TLR4}

Based on real-time PCR analysis, the HCC cell line SMMC-7721 cells constitutively expressed a high level of TLR4, whereas Hep3B cells had low levels; on the other hand, the expression of TLR4 was almost absent in HepG2 and Huh7 cells (Figure 3A). Furthermore, FACS analysis showed that LPS had little effect on TLR4 expression (Figure 3B), suggesting that the different effects of LPS on HCC cell lines might be associated with intrinsic TLR4 expression. In addition, we detected TLR4 expression of the hepatocellular carcinoma cell line MHCC97-H cells which had been confirmed with a strong ability to metastasize. The results also showed that MHCC97-H cells expressed a high level of TLR4 which was not affected by LPS [See Additional file 1, Figure S1A]. LPS significantly promoted the invasion of the MHCC97-H cells through the Matrigel [See Additional file 1, Figure S1B]. The cell 


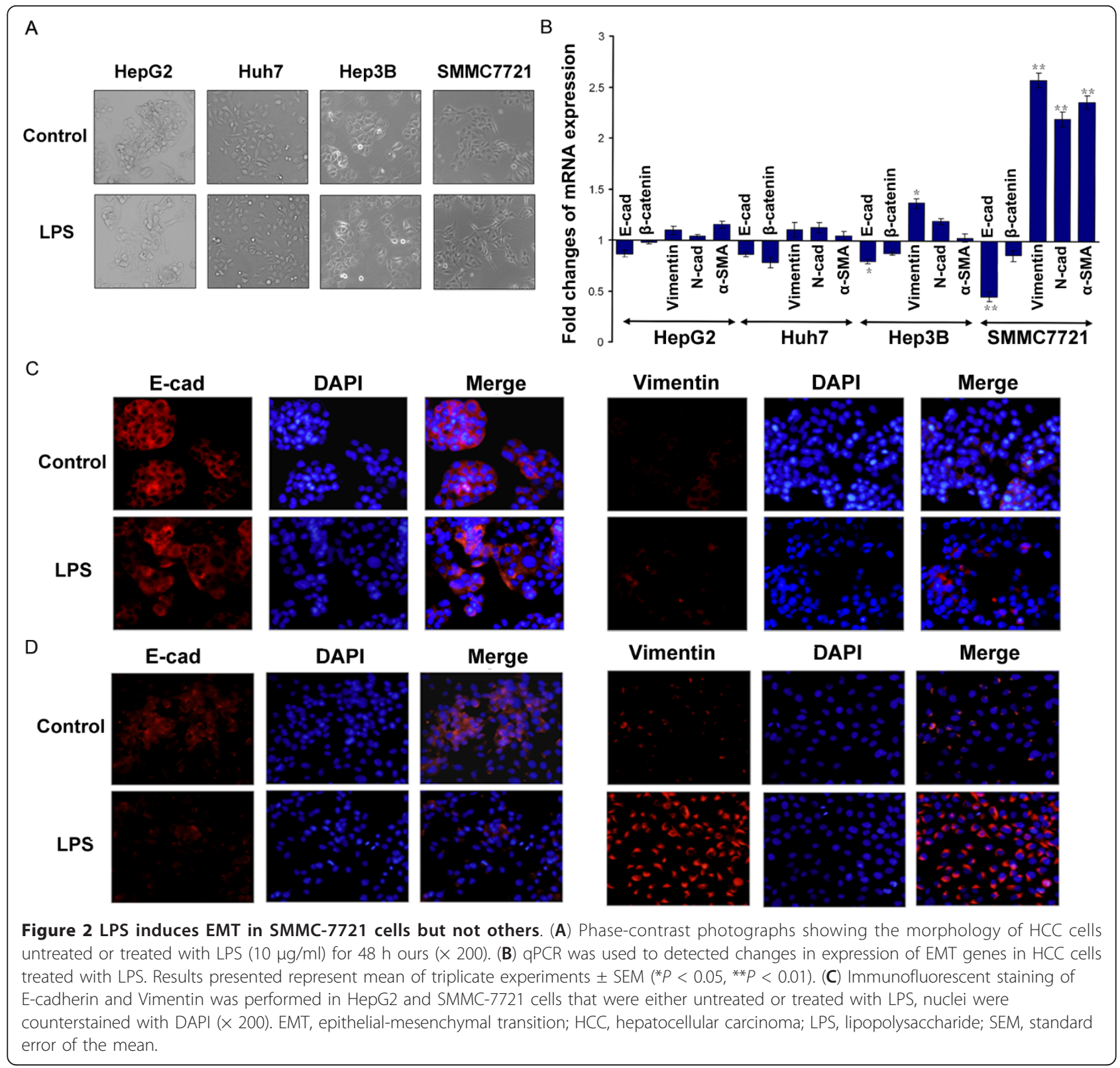

phenotype was also changed, which indicated that the mesenchymal markers (Vimentin and $\mathrm{N}$-cadherin) were upregulated and the epithelial markers (E-cadherin and $\beta$-catenin) were downregulated [See Additional file 1, Figure S1C, D].

To determine whether TLR4 is important in LPS-induced tumor cell metastasis and EMT, we used adeno-associated virus to express TLR4 in HepG2 cells [See, Additional file 1, Figure S2A, B], then pretreated vec-HepG2 and TLR4-HepG2 with LPS. The scratch wound-healing and Matrigel invasion assay showed that overexpression of TLR4 enhanced LPS-induced motility and invasion of HepG2, accompanied by EMT (a decreased expression in epithelial cell markers, such as E-cadherin and $\beta$-catenin, and an increased expression of mesenchymal cell markers, such as Vimentin, $\mathrm{N}$-cadherin, and $\alpha$-SMA. (Figure 4A, $\mathrm{B}, \mathrm{C})$. We then knocked down TLR4 in SMMC-7721 cells with siRNA [See Additional file 1, Figure S 2C, D]; reduction of TLR4 expression in SMMC- 7721 cells reversed the changes in cell motility, invasion and EMT induced by LPS. (Figure 4A, B, C). We next examined whether TLR4 expression influenced LPS-induced tumor cell metastasis in vivo. Transfected cells were stimulated by LPS for 48 hours in vitro and then injected intrasplenically into athymic nude mice. The nude mice splenic vein metastasis models showed that mice injected with LPS-treated TLR4-HepG2 cells had more metastatic nodules on the liver surface than mice with LPS-treated vec-HepG2 cells (Figure 4D, E, 


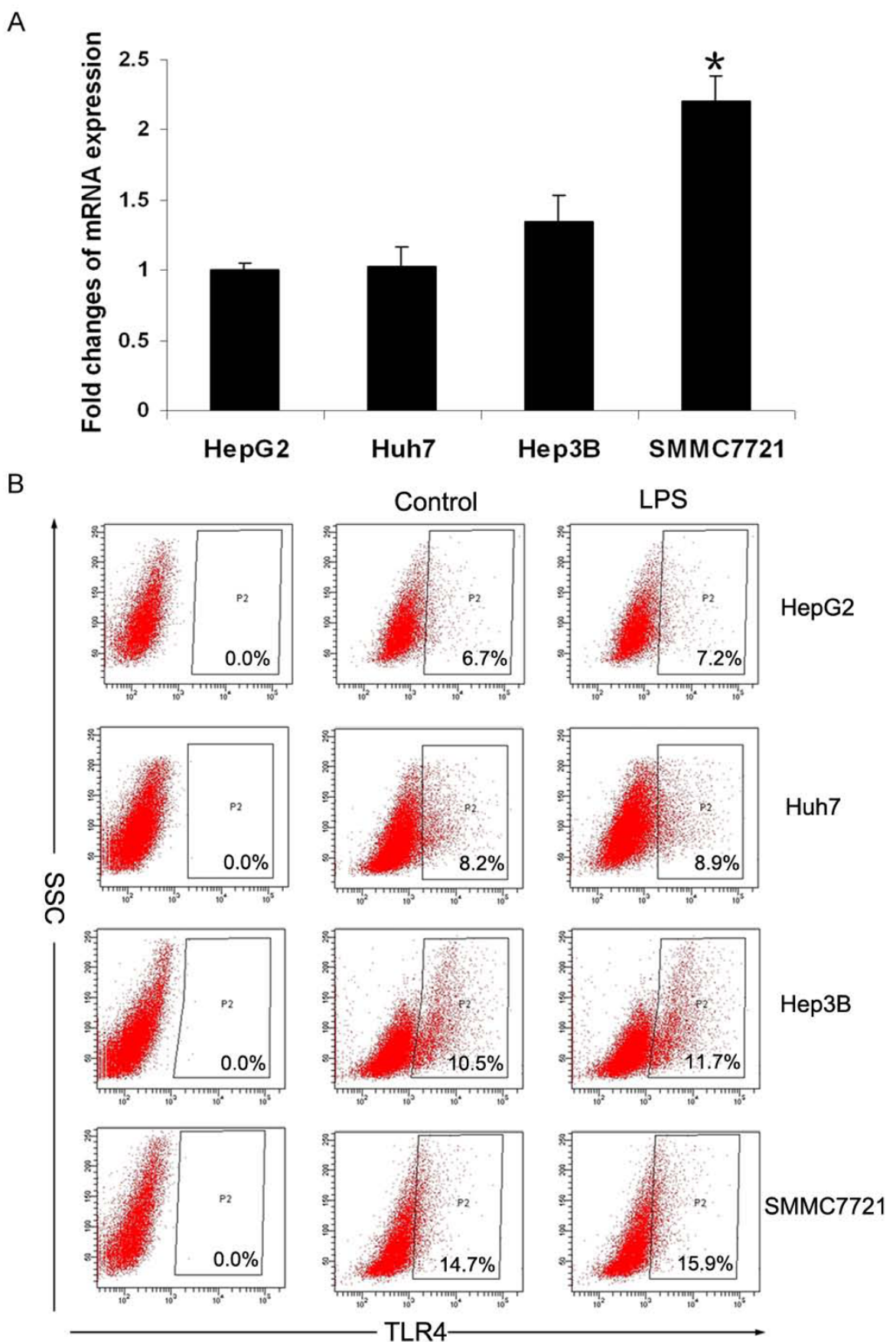

Figure 3 TLR4 expression in different HCC cells lines. (A) qPCR was used to detected TLR4 mRNA expression in HepG2, Huh7, Hep3B and SMMC7721 cells ( $\left.{ }^{*} P<0.05\right)$. (B) FACS analysis for TLR4 protein in HCC cell lines untreated or treated with LPS $(10 \mu \mathrm{g} / \mathrm{ml})$ for 48 hours. The data shown in $A$ and $B$ are from one representative experiment of three performed. HCC, hepatocellular carcinoma; LPS, lipopolysaccharide; TLR4, toll-like receptor 4.

$\mathrm{P}<0.05)$. Reduced TLR4 expression in SMMC-7221 resulted in fewer liver surface metastatic nodules in mice compared to mice injected with LPS-treated SMMC-7721 cells (Figure 4D, F, P $<0.05$ ). These results indicate that LPS-induced cell metastasis and EMT in HCC cells are TLR4 dependent.
LPS-induced EMT involves NF- $\kappa$ B activation and increase of Snail expression

LPS-induced TLR4 signaling has been shown to activate the NF- $\kappa \mathrm{B}$ signaling pathway in various cell types $[8,24]$. To clarify the relationship between NF- $\kappa \mathrm{B}$ activation and the enhanced invasion induced by LPS, we assessed 


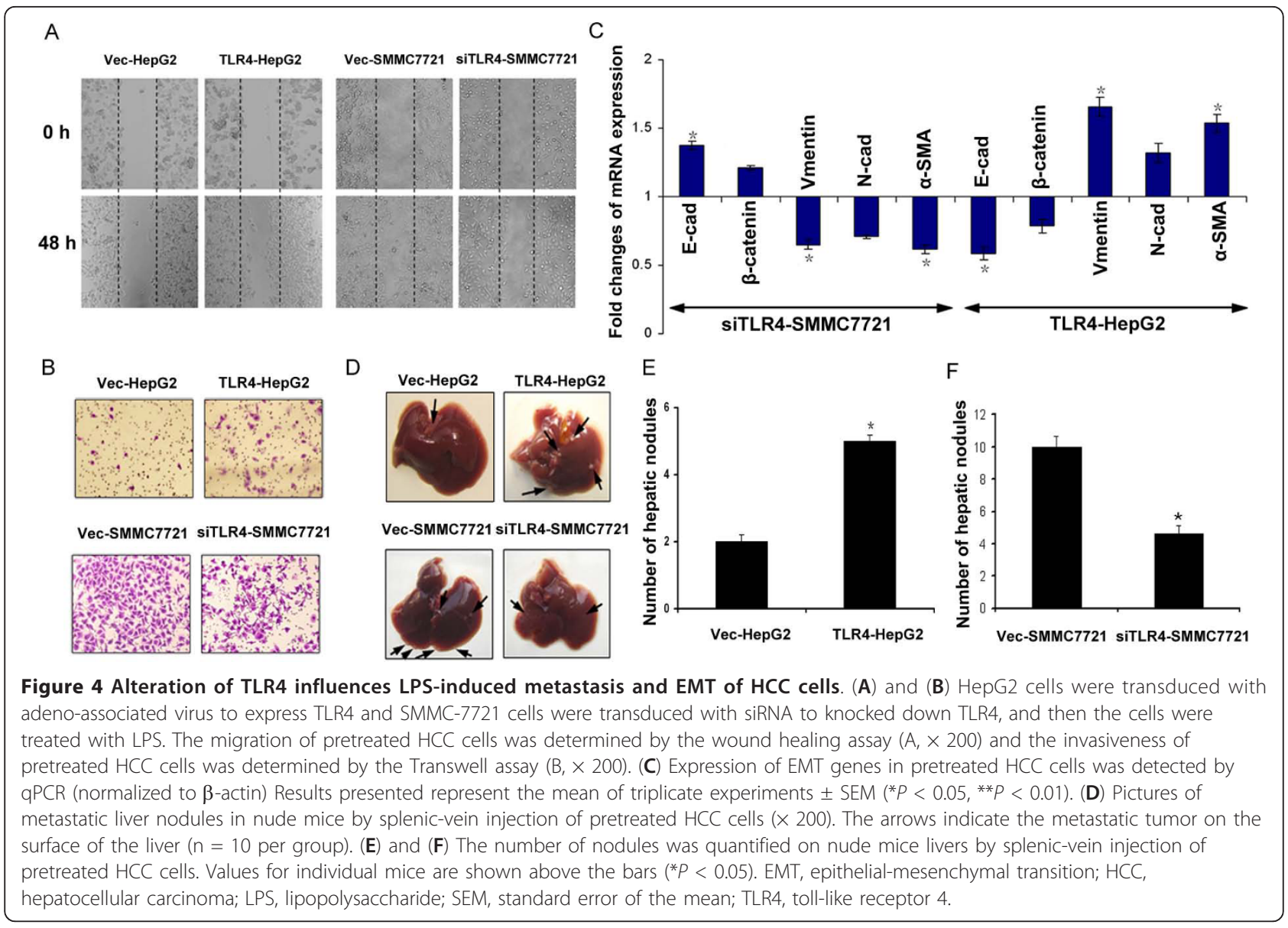

NF- $\kappa$ B activation induced by LPS in HepG 2 and SMMC-7721 cells with pNF- $\kappa$ B-Luc reporter vector. As shown in Figure 5A, LPS treatment resulted in a significant increase of luciferase activity in SMMC-7721 cells $(P<0.05)$, but had no effect in HepG2 cells $(P>0.05)$. Translocation of the p65 subunit of NF- $\kappa \mathrm{B}$ to cell nuclei and NF- $\kappa \mathrm{B}$ p 65 binding activity were evaluated by immunofluoresence; after LPS treatment, p65 subunit translocation significantly increased only in SMMC-7721 cells, whereas no changes were observed in HepG2 cells (Figure 5B). BAY 11-7082 can inhibit phosphorylation of $\mathrm{I} \kappa \mathrm{B} \alpha$ and subsequent NF- $\kappa \mathrm{B}$ nuclear translocation. The results showed that $10 \mu \mathrm{M}$ BAY 11-7082 inhibited NF$\kappa \mathrm{B}$ activity induced by LPS in SMMC-7721 cells significantly $(P<0.05)$ but had no effect in HepG2 cells $(P>$ $0.05)$, which indicated that LPS-induced NF- $\kappa \mathrm{B}$ activation is TLR4 dependent.

Margit $\mathrm{AH}$ et al. had shown that NF- $\kappa \mathrm{B}$ is a pivotal regulator of the EMT process during distinct steps of breast cancer progression [25]. In our study, we examined how NF- $\kappa \mathrm{B}$ activation induced by LPS/TLR4 enhanced expression of transcription factor Snail (Figure 5C, D), a major inducer of EMT. Expression of Snail in SMMC-7721 cells was sufficient to induce EMT as measured by the down modulation of E-cadherin transcript and protein [See Additional file 1, Figure S3]. Increased expression of Snail could also be blocked by treatment with BAY 117082 (Figure 5C, D). Together with the data presented in Figure $5 \mathrm{~A}$, these results showed that treatment with LPS activated NF- $\kappa$ B depending on TLR4 signaling which subsequently caused an increase in Snail and led to EMT and invasion in HCC cells.

\section{Association of TLR4 expression with clinicopathologic characteristics and prognosis of HCC}

In HCC tissues, a total of 101 of 106 (86\%) samples showed positive TLR4 expression (Figure 6A, B). The TLR4 expression levels were found to be significantly higher in HCC tissues with cirrhosis $(P=0.018)$, tumor size $(P=0.030)$, margin $(P=0.019)$, vascular invasion $(P=$ $0.019)$, portal vein thrombosis $(P=0.014)$, and UICC T stage $(P<0.001)$ (Table 1$)$. According to the immunohistochemistry results, all $106 \mathrm{HCC}$ patients were divided into two groups: the high expression group $(\mathrm{n}=64)$ and low expression group $(n=42)$ (Figure 6A, B). Most of the HCC patients within the high expression group had tumor 


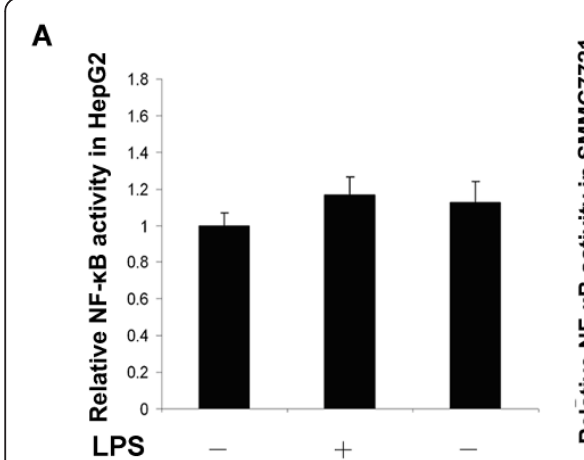

BAY 11-7082 -

B
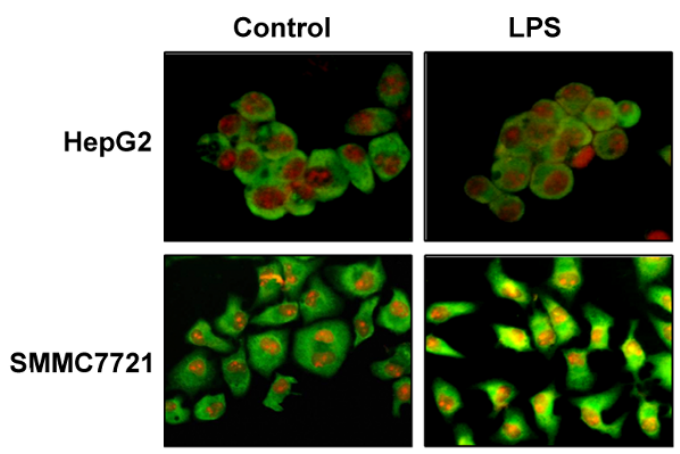

LPS+BAY11-7082
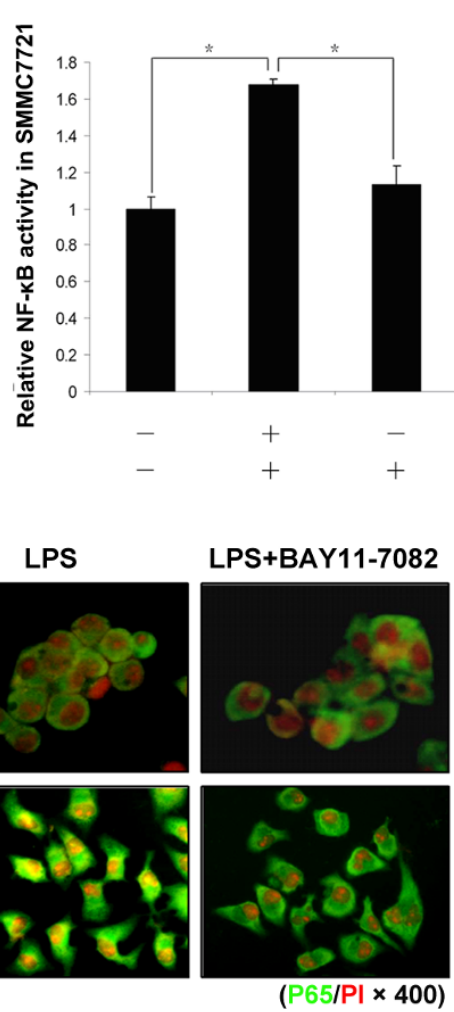

C

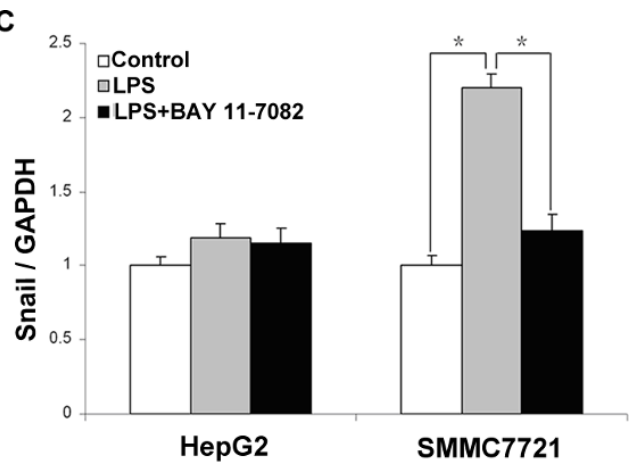

D

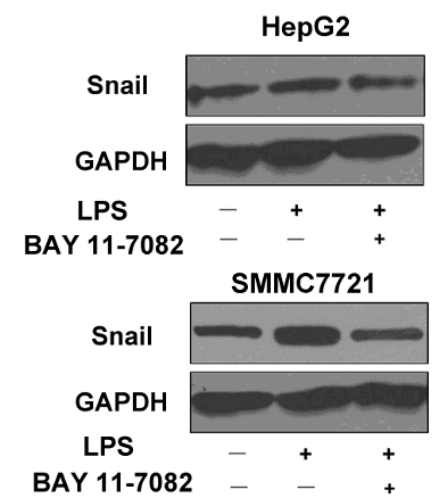

Figure 5 LPS/TLR4 induces cells EMT through activation of NF- $\kappa$ B. (A) A dual luciferase assay was performed 48 hours after adding LPS. Relative NF-kB luciferase activity, normalized to Renilla luciferase activity, was expressed relative to that of control, set at 1.0. LPS resulted in a significant increase of luciferase activity in SMMC-7721 cells, but had no effect in HepG2 cells; NF- $\kappa$ B inhibitors suppress NF- $\kappa$ B activation in SMMC-7721 cells ( $\left.{ }^{*} P<0.05\right)$. (B) Immunofluoresence was used to evaluate the NF- $\kappa$ B p65 binding activity of pretreated HepG2 and SMMC-7721 cells. The p65 subunit of NF- $\kappa$ B in the cytosol was stained green and nuclei were stained red with PI $(\times 400)$. (C) and (D) qPCR and western-blot were used to detect Snail expression in pretreated HepG2 and SMMC-7721 cells. The results showed that LPS upregulated Snail expression in SMMC-7721 cells, but not in HepG2 cells, NF- $\kappa$ B inhibitors suppress Snail expression in SMMC-7721 cells $(* P<0.05$ ). EMT, epithelialmesenchymal transition; HCC, hepatocellular carcinoma; LPS, lipopolysaccharide; NF- $\kappa$ B nuclear factor kappa B; TLR4, toll-like receptor 4.

thrombus, and the IHC results showed that TLR4 expression in tumor thrombus was higher than in normal liver tissue [See Additional file 1, Figure S4]. In addition, HCC patients within the high expression group had either worse cancer-free survival (median cancer-free survival time, 576.83 days versus 1,151.45 days, $P<0.001$; Figure 6 C) or worse overall survival (median survival time, 870.45 days versus $1,689.43$ days, $P<0.001$; Figure $6 \mathrm{D}$ ) than those within the low expression group.

\section{Discussion}

To study the key roles of TLR4 in LPS-induced EMT of HCC cells, we selected four different HCC cells (HepG2, Huh7, Hep3B, and SMMC-7721) and carefully evaluated the direct effect of LPS on the invasive potential of these cells. We demonstrated that LPS could significantly enhance the invasive potential and induce EMT of HCC cells with higher expression of TLR4, which was confirmed to be in a TLR4 dependent manner. Further studies showed that LPS could directly activate NF- $\kappa$ B signaling through TLR4 in HCC cells. Importantly, blocking NF- $\kappa$ B signaling significantly inhibited Snail expression and inhibited EMT occurrence. Finally, we revealed that high expression of TLR4 in HCC tissues was strongly associated with both poor cancer-free survival and overall survival. Our results indicate that TLR4 is necessary for LPS-induced EMT and metastasis in HCC cells, which increases our understanding of the pathogenesis and provides clues for developing new strategies against LPSrelated metastasis of HCC.

This study provides the first evidence that LPS-induced metastasis and EMT of HCC cells is TLR4 dependent. EMT is a key event in the metastasis of tumors from epithelial cells. An imaging study in vivo has shown that carcinoma cells migrate from mouse primary tumors through a process of EMT and that this process is dependent on an inflammatory microenvironment [26]. Recently, the new finding that TNF- $\alpha$ induces EMT in MCF-7 breast cancer cells reinforced the connection between inflammation and EMT [27]. In HCC patients, the level of endotoxin 


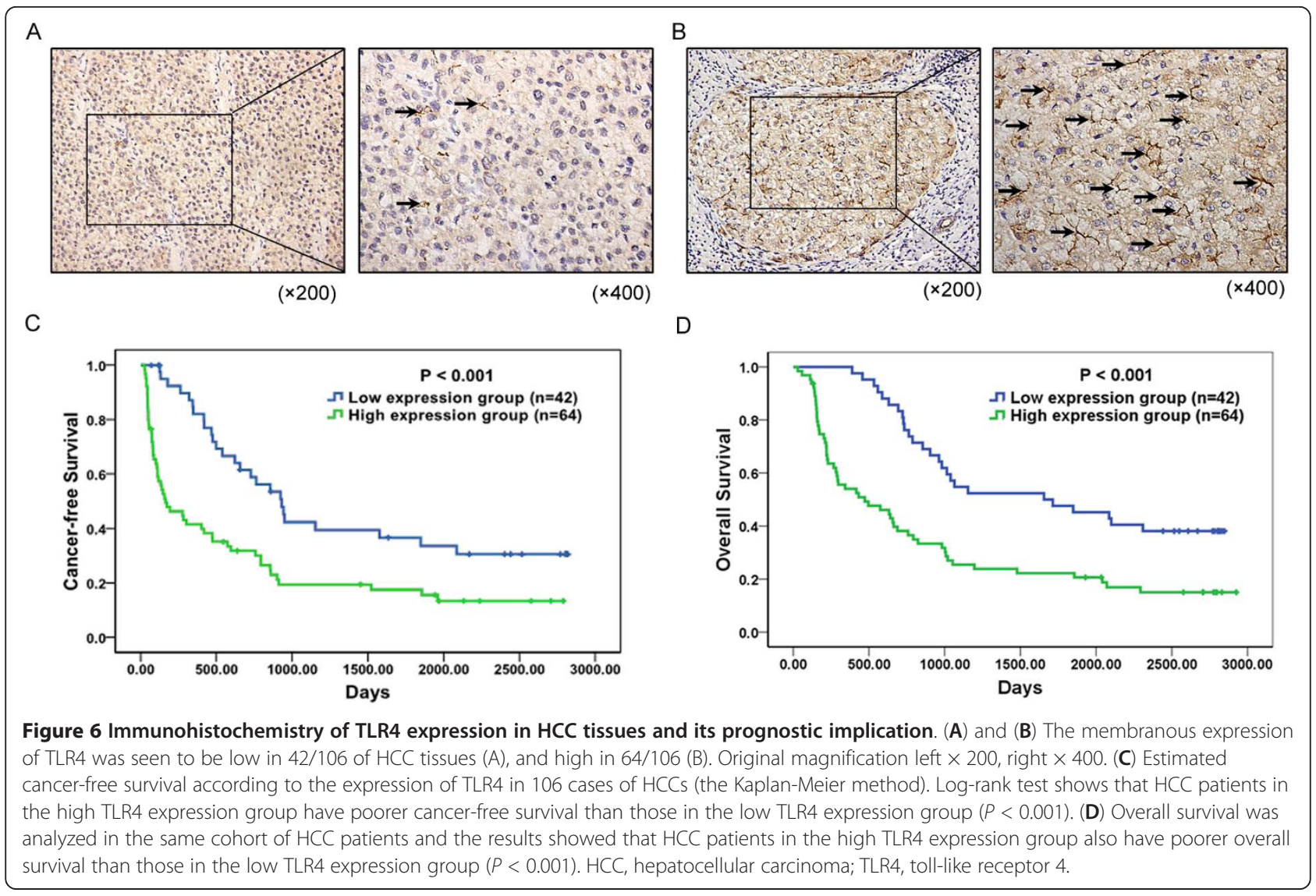

in the portal and peripheral veins has been determined to be higher, which results in a high level of LPS in the portal vein. In this study, four different human HCC cell lines (HepG2, Huh7, Hep3B, and SMMC-7721) were tested in the scratch wound-healing and Matrigel invasion assay. Our results showed that not all tumor cell lines responded in vitro to LPS, the motility and invasion abilities of SMMC-7721 cells were enhanced significantly, and the data of the splenic vein metastasis assay in vivo were consistent with this. However, Liu et al. have inferred that LPS may be ignored by immune systems and may directly promote the invasion abilities of HepG2 and HepG2.2.15 cells [9]. Our experiment showed that LPS had little effect on HepG2 cells; the different experimental methods may have led to the inconsistent results.

Administration of LPS can induce EMT of human IBECs, which makes tumor cells undergo a phenotypic change to produce bipolar cells with a fibroblastic morphology. In these four HCC cells, LPS induced EMT in SMMC-7721 cells but not the others, and SMMC-7721 cells constitutively expressed a high level of TLR4, which might be associated with LPS-induced metastasis and EMT of HCC cells. When we used adeno-associated virus to express TLR4 in HepG2 cells or knocked down TLR4 in SMMC-7721 cells with siRNA, the metastasis and EMT of HCC cells were changed by being treated with LPS. All of the above results highlight a direct link between LPS and tumor cell metastasis. The effect of LPS is possible because SMMC-7721 cells constitutively express TLR-4. Not all tumor cells are positive for TLR-4, and this could depend on the tissue from which the tumor cells originated. Molteni et al. analyzed the responses of tumor cell lines from different origins (melanoma, ovarian carcinoma, neuroblastoma) to LPS in vitro; the results showed that only melanoma cells significantly increased cell adhesion, when triggered with LPS and these effects were associated with the constitutive expression of TLR-4 [28]. Different HCC cell lines also have different expression of TLR4, and LPS-induced EMT in cells is in a TLR4 dependent manner as well. However, notably, HCC development is a multifactorial and complicated process, which has a close association with various risk factors, such as viral infection, alcohol consumption, steatosis, toxic substances and inflammation. In this process, LPS is an important EMT inducer but not the only one. Many gene alterations and cytokines also could induce EMT and promote metastasis [29]. Therefore, although HCC cells with low expression or even a lack of TLR4 are not susceptible to LPS, they might perform EMT induced by other TLR4-independent mechanisms. 
Table 1 Correlations between TLR4 expression and clinicopathologic variables of HCC.

\begin{tabular}{|c|c|c|c|c|}
\hline \multirow[t]{2}{*}{ Clinicopathologic Parameters } & \multirow[t]{2}{*}{ Number } & \multicolumn{2}{|c|}{$\begin{array}{l}\text { TLR4 expression } \\
\text { levels }\end{array}$} & \multirow[t]{2}{*}{$P$-Value } \\
\hline & & Low & High & \\
\hline \multicolumn{5}{|l|}{ Age (years) } \\
\hline$\leq 60$ & 83 & 36 & 47 & 0.134 \\
\hline$>60$ & 23 & 6 & 17 & \\
\hline \multicolumn{5}{|l|}{ Gender } \\
\hline Male & 88 & 36 & 52 & 0.546 \\
\hline Female & 18 & 6 & 12 & \\
\hline \multicolumn{5}{|l|}{ Cirrhosis } \\
\hline Absence & 42 & 17 & 35 & $0.018^{*}$ \\
\hline Presence & 64 & 35 & 29 & \\
\hline \multicolumn{5}{|l|}{ AFP (ng/mL) } \\
\hline$\leq 20$ & 24 & 11 & 13 & 0.479 \\
\hline$>20$ & 82 & 31 & 51 & \\
\hline \multicolumn{5}{|l|}{$\mathrm{HBsAg}$} \\
\hline Negative & 15 & 7 & 9 & 0.714 \\
\hline Positive & 90 & 35 & 55 & \\
\hline \multicolumn{5}{|l|}{ Tumor size $(\mathrm{cm})$} \\
\hline$\leq 5$ & 35 & 19 & 16 & $0.030^{*}$ \\
\hline$>5$ & 71 & 23 & 48 & \\
\hline \multicolumn{5}{|l|}{ Tumor margin } \\
\hline Clear & 34 & 19 & 15 & $0.019^{*}$ \\
\hline Invovled & 72 & 23 & 49 & \\
\hline \multicolumn{5}{|l|}{ Satellite lesion } \\
\hline Absence & 77 & 32 & 45 & 0.507 \\
\hline Presence & 29 & 10 & 19 & \\
\hline \multicolumn{5}{|l|}{ Vascular invasion } \\
\hline Absence & 23 & 14 & 9 & $0.019^{*}$ \\
\hline Presence & 83 & 28 & 55 & \\
\hline \multicolumn{5}{|l|}{ Portal vein thrombosis } \\
\hline Absence & 74 & 35 & 39 & $0.014^{*}$ \\
\hline Presence & 32 & 7 & 25 & \\
\hline \multicolumn{5}{|l|}{ UICC T stage } \\
\hline $\mathrm{T} 1$ & 16 & 13 & 3 & $<0.001^{*}$ \\
\hline $\mathrm{T} 2$ & 60 & 26 & 34 & \\
\hline $\mathrm{T} 3$ & 30 & 3 & 27 & \\
\hline
\end{tabular}

$\left({ }^{*} P<0.05\right)$

NF- $\kappa \mathrm{B}$ activation is well known to play an important role in responses to LPS via TLR-4 [8,24]. Previous studies have shown that LPS may be able to induce NF- $\kappa \mathrm{B}$ activation in colon and pancreatic cancer cells [30,31], which strongly suggests that LPS can act not only on immune cells but also on some cancer cells from epithelial cells. In the current study, we found that ligation of LPS and TLR4 could activate the NF- $\kappa$ B pathway in SMMC-7721 cells, but not in HepG2 cells. Furthermore, activation of NF- $\kappa \mathrm{B}$ is involved in the invasion and metastasis of HCC. Many studies have shown that NF- $\kappa$ B is a key regulator of Snail expression in cancer cell lines and metastatic tumor samples [32-35]. In our study, activation of NF- $\kappa \mathrm{B}$ in SMMC-7721 cells up-regulated Snail expression, which was a prerequisite for these cells to undergo an EMT toward an invasive, metastatic tumor phenotype. Snail is identified as a transcription factor in the control of EMT, and expression of Snail represses expression of E-cadherin and induces EMT in breast cancer cells, indicating that Snail plays a fundamental role in EMT $[36,37]$. To confirm the contribution of NF- $\kappa$ B activation to the enhanced invasive ability and EMT, we used BAY-11-7082 to inhibit NF- $\kappa$ B activation in SMMC-7721 cells, and the inhibitor not only reduced NF- $\kappa$ B activation, but also down-regulated Snail expression. Our data strongly suggest that activation of the NF$\kappa \mathrm{B}$ pathway by LPS is TLR4-dependent and increases Snail expression to induce EMT.

TLR4 expression has been described in different human tumors [10,12-16]. Gonzalez-Reyes et al. have showed that TLR4 expression in breast carcinomas was associated with an increased incidence of metastasis and has prognostic significance [14]. Cammarota et al. analyzed 116 tissue samples from patients with different stages of colorectal disease and found that adenocarcinoma patients with higher TLR-4 expression in the stromal compartment had a significantly increased risk of disease progression and relapsed significantly earlier than those with lower expression levels [38]. Interestingly, analysis of the association of TLR4 expression and the clinicopathological characteristics of 106 HCC patients reveals that TLR4 expression is significantly correlated with margin, vascular invasion, portal vein thrombosis, and so on, which are widely accepted markers for metastasis and poor prognosis of HCC $[39,40]$. The KaplanMeier analysis shows that the HCC patients with high TLR4 expression in general had a shorter cancer-free interval and a worse overall survival than those with low expression, suggesting that TLR4 may be a useful biomarker of HCC metastasis and recurrence.

In conclusion, our study has shown for the first time that LPS-induced EMT and the invasive potential of HCC cells is in a TLR4 dependent manner and that activation of the NF- $\kappa$ B-Snail regulatory axis may function as a therapeutic target. Furthermore, we have demonstrated that high expression of TLR4 in HCC tissues significantly correlates with metastasis and recurrence of HCC. Our data suggest TLR4 as a novel prognostic marker and a potential therapeutic target for LPS-induced EMT and metastasis of HCC.

\section{Conclusions}

Our results indicate that TLR4 signaling is required for LPS-induced EMT, tumor cell invasion and metastasis, which provide molecular insights for LPS-related pathogenesis and a basis for developing new strategies against metastasis in HCC. 


\section{Additional material}

\section{Additional file 1: Supplemental figures and tables. Figure S1.} MHCC97-H cells with high expression of TLR4 were induced metastasis and EMT by LPS. (A) FACS analysis for TLR4 expression in MHCC97-H cell line untreated or treated with LPS $(10 \mu \mathrm{g} / \mathrm{ml})$ for 48 hours. (B) The invasiveness of MHCC $97-H$ cells pretreated with LPS $(10 \mu \mathrm{g} / \mathrm{ml})$ for 48 hours was determined by Transwell assay $\left(\times 200,{ }^{*} P<0.05\right)$. (C) qPCR was used to detected changes in the expression of EMT genes in MHCC97$\mathrm{H}$ cells treated with LPS. Results presented represent mean of triplicate experiments $\pm S E M(* P<0.05)$. (D) Immunofluorescent staining of $E$ cadherin and Vimentin was performed in MHCC97-H cells that were either untreated or treated with LPS, nuclei were counterstained with DAPI $(x$ 400). Figure S2. Upregulation of TLR4 expression in HepG2 cells and downregulation of TLR4 expreesion in SMMC-7721 cells. (A) and (B) Adeno-associated virus was used to express TLR4 in HepG2 cells. TLR4 mRNA expression was detceted by $q P C R\left(A,{ }^{*} P<0.05\right)$ and protein expression was detected by western-blot (B). (C) and (D) siRNA was used to knock down TLR4 expression in SMMC-7721 cells. TLR4 mRNA expression was detceted by $\mathrm{qPCR}\left(\mathrm{C},{ }^{*} P<0.05\right)$ and protein expression was detceted by western-blot (D). Figure S3. Upregulation of Snail induced EMT in SMMC-7721 cells. Adeno-associated virus was used to express Snail in SMMC-7721 cells. E-cad mRNA expression was detected by qPCR ( $A^{*} P<$ 0.05), and E-cad protein expression was evaluated by western-blot (B). The data shown in $A$ and $B$ are from one representative experiment of three performed. Figure S4. High expression of TLR4 in HCC thrombus. (A) H \& E staining was performed to show thrombus in HCC tissues ( $\times$ 200). (B) Immunohistochemistry was performed to show TLR4 expression in HCC thrombus as well as surrounding normal liver tissue $(\times 200)$, (a) HCC thrombus, original magnification $\times 400$ (b) normal liver tissue, original magnification $\times 400$. BV, blood vessels; $T$, thrombus; $\mathrm{N}$, normal liver tissue. Table S1. Description: Sequence of the oligonucleotides for real-time PCR assays

\section{Abbreviations}

ANOVA: analysis of variance; $a-S M A$ : $a-s m o o t h$ muscle actin; (D)MEM: (Dulbecco's) modified Eagle's medium; EDTA: ethylenediamine tetraacetic acid; EMT: epithelial to mesenchymal transition; FBS: fetal bovine serum; FITC: fluorescein isothiocyanate; HCC: hepatocellular carcinoma; IBECs: intrahepatic biliary epithelial cells; IHC: immunohistochemisty; LPS: lipopolysaccharide; NF-kB; nuclear factor kappa B; qPCR: quantitative realtime polymerase chain reaction; SEM: standard error of the mean; TLR4: tolllike receptor 4.

\section{Acknowledgements}

This project was supported by Key project of National Natural Science Foundation of China (Grant NO: 81030041); Key Basic Research Project of China (Grant NO: 2010CB945600, 2011CB966200); National Natural Science Foundation of China (Grant NO: 30901722, 31171321, 81000970, 81101622); Special Funds for National Key Sci-Tech Special Project of China (Grant NO: 2008ZX10002-019, 2008ZX10002-025); Shanghai Science and Technology Committee (Grant NO: 10ZR1439600, 11ZR1449500, 10411963100 , 10ZR1439900); Science Fund for Creative Research Groups, NSFC, China (Grant NO: 30921006); Stem Cell and Medicine Research Center's Innovation Research Program (Grant NO: SCMRC1102); 2011 Ph.D. Graduate Innovation Fund Project (Grant NO: 27).

\section{Authors' contributions \\ YYJ, ZPH, KS and LXW participated in the design and performance of the study. SSZ, JH and YL provided clinical data and performed statistical analysis. RL, LG, XZ and QDZ carried out cell culture, molecular genetic studies and the mouse experiment. MCW and LXW conceived of the study and participated in its design and coordination. The manuscript was drafted by YYJ, ZPH and KS, and reviewed by all authors. All authors approved the final version of the manuscript to be published.}

\section{Competing interests}

The authors declare that they have no competing interests.
Received: 15 February 2012 Accepted: 31 August 2012 Published: 31 August 2012

\section{References}

1. Cordon-Cardo C, Prives C: At the crossroads of inflammation and tumorigenesis. J Exp Med 1999, 190:1367-1370.

2. Nolan JP, Leibowitz Al: Endotoxins in liver disease. Gastroenterology 1978, 75:765-766.

3. Triger DR, Boyer TD, Levin J: Portal and systemic bacteraemia and endotoxaemia in liver disease. Gut 1978, 19:935-939.

4. Schwabe RF, Seki E, Brenner DA: Toll-like receptor signaling in the liver. Gastroenterology 2006, 130:1886-1900.

5. Iwasaki A, Medzhitov R: Toll-like receptor control of the adaptive immune responses. Nat Immunol 2004, 5:987-995.

6. Pidgeon GP, Harmey JH, Kay E, Da Costa M, Redmond HP, BouchierHayes DJ: The role of endotoxin/lipopolysaccharide in surgically induced tumour growth in a murine model of metastatic disease. $\mathrm{Br} J$ Cancer 1999, 81:1311-1317.

7. Harmey JH, Bucana CD, Lu W, Byrne AM, McDonnell S, Lynch C, BouchierHayes D, Dong Z: Lipopolysaccharide-induced metastatic growth is associated with increased angiogenesis, vascular permeability and tumor cell invasion. Int J Cancer 2002, 101(5):415-422.

8. Wang JH, Manning BJ, Wu QD, Blankson S, Bouchier-Hayes D, Redmond HP Endotoxin/lipopolysaccharide activates NF-kappa B and enhances tumor cell adhesion and invasion through a beta 1 integrin-dependent mechanism. J Immunol 2003, 170:795-804

9. Liu X, Liang J, Li G: Lipopolysaccharide promotes adhesion and invasion of hepatoma cell lines HepG2 and HepG2.2.15. Mol Biol Rep 2010, 37:2235-2239.

10. Ikebe M, Kitaura Y, Nakamura M, Tanaka H, Yamasaki A, Nagai S, Wada J, Yanai K, Koga K, Sato N, Kubo M, Tanaka M, Onishi H, Katano M: Lipopolysaccharide (LPS) increases the invasive ability of pancreatic cancer cells through the TLR4/MyD88 signaling pathway. I Surg Oncol 2009, 100:725-731.

11. Akira S, Takeda K: Toll-like receptor signalling. Nat Rev 2004, 4:499-511.

12. Hua D, Liu MY, Cheng ZD, Qin XJ, Zhang HM, Chen Y, Qin GJ, Liang G, Li JN, Han XF, Liu DX: Small interfering RNA-directed targeting of Toll-like receptor 4 inhibits human prostate cancer cell invasion, survival, and tumorigenicity. Mol Immunol 2009, 46:2876-2884.

13. Yu LX, Yan HX, Liu Q, Yang W, Wu HP, Dong W, Tang L, Lin Y, He YQ, Zou SS, Wang C, Zhang HL, Cao GW, Wu MC, Wang HY: Endotoxin accumulation prevents carcinogen-induced apoptosis and promotes liver tumorigenesis in rodents. Hepatology 2010, 52:1322-1333.

14. Gonzalez-Reyes S, Marin L, Gonzalez L, Gonzalez LO, del Casar JM, Lamelas ML, Gonzalez-Quintana JM, Vizoso FJ: Study of TLR3, TLR4 and TLR9 in breast carcinomas and their association with metastasis. BMC Cancer 2010, 10:665.

15. $X u Z$, Ren T, Xiao $C, L i H, W u T$ : Nickel promotes the invasive potential of human lung cancer cells via TLR4/MyD88 signaling. Toxicology 2011, 285:25-30.

16. Wang EL, Qian ZR, Nakasono M, Tanahashi T, Yoshimoto K, Bando Y, Kudo E, Shimada M, Sano T: High expression of Toll-like receptor 4/myeloid differentiation factor 88 signals correlates with poor prognosis in colorectal cancer. Br J Cancer 2010, 102:908-915.

17. Larue L, Bellacosa A: Epithelial-mesenchymal transition in development and cancer: role of phosphatidylinositol 3' kinase/AKT pathways. Oncogene 2005, 24:7443-7454.

18. Zhao L, Yang R, Cheng L, Wang M, Jiang Y, Wang S: LPS-induced epithelial-mesenchymal transition of intrahepatic biliary epithelial cells. J Surg Res 2011, 171:819-25.

19. Wu F, Yang LY, Li YF, Ou DP, Chen DP, Fan C: Novel role for epidermal growth factor-like domain 7 in metastasis of human hepatocellular carcinoma. Hepatology 2009, 50:1839-1850.

20. Yang MH, Chen CL, Chau GY, Chiou SH, Su CW, Chou TY, Peng WL, Wu JC: Comprehensive analysis of the independent effect of twist and snail in promoting metastasis of hepatocellular carcinoma. Hepatology 2009, 50:1464-1474.

21. Zhang $X$, Liu S, Hu T, Liu S, He Y, Sun S: Up-regulated microRNA-143 transcribed by nuclear factor kappa B enhances hepatocarcinoma metastasis by repressing fibronectin expression. Hepatology 2009, 50:490-499. 
22. Sun T, Zhao N, Zhao XL, Gu Q, Zhang SW, Che N, Wang XH, Du J, Liu YX, Sun $B C$ : Expression and functional significance of Twist1 in hepatocellular carcinoma: its role in vasculogenic mimicry. Hepatology 2010, 51:545-556.

23. Zhang J, Chen Y, Xin XL, Li QN, Li M, Lin LP, Geng MY, Ding J: Oligomannurarate sulfate blocks tumor growth by inhibiting NF-kappaB activation. Acta Pharmacol Sin 2010, 31:375-381.

24. Szajnik M, Szczepanski MJ, Czystowska M, Elishaev E, Mandapathil M, Nowak-Markwitz E, Spaczynski M, Whiteside TL: TLR4 signaling induced by lipopolysaccharide or paclitaxel regulates tumor survival and chemoresistance in ovarian cancer. Oncogene 2009, 28:4353-4363.

25. Huber MA, Azoitei N, Baumann B, Grunert S, Sommer A, Pehamberger H, Kraut N, Beug H, Wirth T: NF-kappaB is essential for epithelialmesenchymal transition and metastasis in a model of breast cancer progression. J Clin Invest 2004, 114:569-581.

26. Condeelis J, Segall JE: Intravital imaging of cell movement in tumours. Nat Rev Cancer 2003, 3:921-930.

27. Dong R, Wang Q, He XL, Chu YK, Lu JG, Ma QJ: Role of nuclear factor kappa $B$ and reactive oxygen species in the tumor necrosis factor-alphainduced epithelial-mesenchymal transition of MCF-7 cells. Braz J Med Biol Res 2007, 40:1071-1078.

28. Molteni M, Marabella D, Orlandi C, Rossetti C: Melanoma cell lines are responsive in vitro to lipopolysaccharide and express TLR-4. Cancer Lett 2006, 235:75-83.

29. van Zijl F, Zulehner G, Petz M, Schneller D, Kornauth C, Hau M, Machat G, Grubinger M, Huber H, W Mikulits: Epithelial to mesenchymal transition in hepatocellular carcinoma. Future Oncol 2009, 5:1169-1179.

30. Nakashima H, Nakamura M, Yamaguchi H, Yamanaka N, Akiyoshi T, Koga K, Yamaguchi K, Tsuneyoshi M, Tanaka M, Katano M: Nuclear factor-kappaB contributes to hedgehog signaling pathway activation through sonic hedgehog induction in pancreatic cancer. Cancer Res 2006, 66:7041-7049.

31. Kojima M, Morisaki T, Izuhara K, Uchiyama A, Matsunari Y, Katano M, Tanaka M: Lipopolysaccharide increases cyclo-oxygenase-2 expression in a colon carcinoma cell line through nuclear factor-kappa B activation. Oncogene 2000, 19:1225-1231.

32. Wu Y, Deng J, Rychahou PG, Qiu S, Evers BM, Zhou BP: Stabilization of snail by NF-kappaB is required for inflammation-induced cell migration and invasion. Cancer Cell 2009, 15:416-428.

33. Barbera MJ, Puig I, Dominguez D, Julien-Grille S, Guaita-Esteruelas S, Peiro S, Baulida J, Franci C, Dedhar S, Larue L, García de Herreros A: Regulation of Snail transcription during epithelial to mesenchymal transition of tumor cells. Oncogene 2004, 23:7345-7354

34. Criswell TL, Arteaga CL: Modulation of NFkappaB activity and E-cadherin by the type III transforming growth factor beta receptor regulates cell growth and motility. J Biol Chem 2007, 282:32491-32500.

35. Franco DL, Mainez J, Vega S, Sancho P, Murillo MM, de Frutos CA, Del Castillo G, Lopez-Blau C, Fabregat I, Nieto MA: Snail1 suppresses TGF-betainduced apoptosis and is sufficient to trigger EMT in hepatocytes. J Cell Sci 2010, 123:3467-3477.

36. Batlle E, Sancho E, Franci C, Dominguez D, Monfar M, Baulida J, Garcia De Herreros A: The transcription factor snail is a repressor of E-cadherin gene expression in epithelial tumour cells. Nat Cell Biol 2000, 2:84-89.

37. Cano A, Perez-Moreno MA, Rodrigo I, Locascio A, Blanco MJ, del Barrio MG, Portillo F, Nieto MA: The transcription factor snail controls epithelialmesenchymal transitions by repressing E-cadherin expression. Nat Cell Biol 2000, 2:76-83.

38. Cammarota R, Bertolini V, Pennesi G, Bucci EO, Gottardi O, Garlanda C, Laghi L, Barberis MC, Sessa F, Noonan DM, Albini A: The tumor microenvironment of colorectal cancer: stromal TLR-4 expression as a potential prognostic marker. J Trans/ Med 2010, 8:112.

39. Velazquez RF, Rodriguez M, Navascues CA, Linares A, Perez R, Sotorrios NG, Martinez I, Rodrigo L: Prospective analysis of risk factors for hepatocellular carcinoma in patients with liver cirrhosis. Hepatology 2003, 37:520-527.

40. Poon RT, Fan ST, Lo CM, Liu CL, Wong J: Difference in tumor invasiveness in cirrhotic patients with hepatocellular carcinoma fulfilling the Milan criteria treated by resection and transplantation: impact on long-term survival. Ann Surg 2007, 245:51-58.

\section{Pre-publication history}

The pre-publication history for this paper can be accessed here: http://www.biomedcentral.com/1741-7015/10/98/prepub

doi:10.1186/1741-7015-10-98

Cite this article as: Jing et al:: Toll-like receptor 4 signaling promotes epithelial-mesenchymal transition in human hepatocellular carcinoma induced by lipopolysaccharide. BMC Medicine 2012 10:98.

\section{Submit your next manuscript to BioMed Central and take full advantage of:}

- Convenient online submission

- Thorough peer review

- No space constraints or color figure charges

- Immediate publication on acceptance

- Inclusion in PubMed, CAS, Scopus and Google Scholar

- Research which is freely available for redistribution

Submit your manuscript at www.biomedcentral.com/submit
C Biomed Central 